\title{
Impact des Intrusions Paysannes sur la Physionomie et la Dynamique de la Végétation de la Forêt Classée de Laouda au Centre-Ouest de la Côte d'Ivoire
}

\author{
N'guessan Yao Joachim, Doctorant \\ Koné Moussa, Maître de Conférences \\ Douffi Kouakou Guy-Casimir, Doctorant \\ Gnahoré Eric, Doctorant \\ Unité de Formation et de Recherche en Sciences de la Nature, \\ Université Nangui Abrogoua, Côte d'Ivoire
}

Doi:10.19044/esj.2019.v15n24p360 URL:http://dx.doi.org/10.19044/esj.2019.v15n24p360

\section{Résumé}

La disparition des forêts en Côte d'Ivoire est imputable aux intrusions paysannes dans les aires protégées dont les forêts classées. Cette disparition a pour conséquences la perte de biodiversité. La forêt classée de Laouda, objet de la présente étude, est fortement pénétrée par les paysans à des fins de cultures. Pour mieux comprendre l'impact de ces intrusions, cette étude se propose d'évaluer la dynamique entre 1986 et 2017 à partir de l'imagerie satellitaire, puis de caractériser les occupations ou utilisations du sol de la forêt classée. La méthode de la classification supervisée par le réseau de neurone a été utilisée sur les images Landsat TM et OLI de 1986 et de 2017. Cela a été précédé par la caractérisation physionomique des types de végétation. Les différentes formations végétales présentes dans cette forêt classée sont les forêts denses, les forêts secondaires, les plantations forestières et les jachères. Ces habitats ont de faibles valeurs de densité (904,16 à 1608,33 tiges/ha) et d'aire basale (1,06 à 4,3 $\left.\mathrm{m}^{2} / \mathrm{ha}\right)$. La dynamique temporelle de l'occupation du sol entre 1986 et 2017 a montré une régression des forêts au profit des cultures et des jachères. Le processus de dégradation des formations forestières est la dissection et la fragmentation pour respectivement les forêts denses et les forêts secondaires. Les artificialisations ou apparitions ont été observées au niveau des jachères et cultures, avec respectivement le processus de création et d'agrégation. Pendant cette période, $14,27 \%$ soit 568,37 ha du paysage occupé par les forêts ont été converti en cultures et en jachères. Cette situation est consécutive à la pression démographique et au développement des cultures d'exportations. 
Mots-clés: Déforestation, Dynamique de la végétation, Télédétection, Forêt classée de Laouda, Côte d'Ivoire

\title{
Impact of Peasant Intrusions on the Physiognomy and Vegetation Dynamics of the Laouda Classified Forest in Central-West Côte d'Ivoire
}

\author{
N'guessan Yao Joachim, Doctorant \\ Koné Moussa, Maître de Conférences \\ Douffi Kouakou Guy-Casimir, Doctorant \\ Gnahoré Eric, Doctorant
}

Unité de Formation et de Recherche en Sciences de la Nature,

Université Nangui Abrogoua, Côte d'Ivoire

\begin{abstract}
Forests disappearance in Côte d'Ivoire is attributable to peasant intrusions into protected areas, including classified forests. The loss of biodiversity is a consequence of this disappearance. Laouda classified forest, which is the subject of this study, is strongly penetrated by peasants for crops. To better understand the impact of these intrusions, this paper focuses on evaluating the dynamics between 1986 and 2017 starting from the satellite imagery, and then to characterize land covers or land uses of the classified forest. The supervised classification method by neuron network was used on the Landsat TM and OLI images of 1986 and 2017. This was preceded by physiognomic characterization of vegetation types. The different vegetation formations present in this classified forest are dense forests, secondary forests, regenerated forest, and fallows. These habitats have low density values (904.16 to 608.33 stems / ha) and basal area (1.06 to $4.3 \mathrm{~m}^{2} / \mathrm{ha}$ ). The dynamics over time of land use between 1986 and 2017 showed a regression of forests in favor of crops and fallows. Forest formations degradation process is dissection and fragmentation for respectively dense forests and secondary forests. Artificializations or apparitions have been observed at the level of fallows and crops, with the process of creation and aggregation, respectively. During this period, $14.27 \%$ or 568.37 ha of the landscape occupied by the forests was converted into crops and fallows. This situation occurs due to
\end{abstract}


demographic pressure and export crops development.

Keywords: Deforestation, Vegetation dynamic, Remote sensing, Laouda classified Forest, Côte d'Ivoire

\section{Introduction}

La déforestation est une véritable problématique à travers le monde. En Côte d'Ivoire, le phénomène demeure alarmant malgré les nombreuses initiatives visant à attirer l'attention sur les forêts dans le monde entier (FAO, 2011). Estimé à environ 16 millions d'hectares en 1900 (Aké-Assi \& Dian, 1988), le couvert forestier dense est aujourd'hui estimé à 1,38 millions ha (Koné et al., 2014). Cette situation est le résultat de l'exploitation abusive combinée au développement des cultures de spéculation (Koné et al., 2014). A cet effet, de vastes étendues de forêts ont été défrichées pour créer d'immenses plantations des cultures de rentes telles que le café, le cacao, le palmier à huile, l'hévéa, l'ananas, etc.

En outre, la forte croissance démographique accentuée par une immigration incontrôlée constitue un facteur important dans la perte des forêts ivoiriennes (Adou Yao \& N'Guessan, 2005). La forte pression anthropique sur les forêts constitue une menace majeure pour la diversité végétale et animale abritées par ces écosystèmes forestiers. La déforestation en Côte d'Ivoire a touché toutes les régions et particulièrement celles du centre ouest qui a perdu $97 \%$ de son couvert forestier dense de 1960 à 2000 (Koné, 2015; Koné et al., 2014). Cette partie du territoire ivoirien a fait l'objet de nombreux travaux de recherche (Chauveau et al., 1981; Koné et al., 2010; Kouamé, 2000; Kouassi et al., 2009; N'Dri \& Gnahoua, 2008; OIBT, 2004; Sagne et al., 2008). Certains de ces travaux ont traité des interrelations entre les cultures et la diversité végétale. Ils ont permis d'avoir une idée de la flore des différentes unités de végétation. Mais, ces études n’ont pas concerné le suivi de l'évolution des unités de végétation sur une longue période. La plupart de ces études ont eu lieu dans la forêt de Téné et la forêt de Sangoué, laissant la forêt classée de Laouda presque inconnue. La présente étude qui est donc la première à s'intéresser à cette forêt classée du point de vue cartographique et physionomique, vise à caractériser l'impact des intrusions paysannes sur la physionomie et la dynamique de sa végétation. Il s'agit spécifiquement :

- d'analyser la dynamique spatio-temporelle de ses formations végétales entre 1986 et 2017 ;

- de caractériser les occupations du sol de la forêt classée de Laouda. 


\section{Matériel et méthodes}

\subsection{Site d'étude}

La forêt classée de Laouda (FCL) est localisée dans la région du Gôh, précisément dans le département d'Oumé, au centre-ouest de la Côte d'Ivoire entre les latitudes nord $6^{\circ} 14^{\prime} 7^{\prime \prime}$ et $6^{\circ} 19^{\prime} 28^{\prime \prime}$ et entre les longitudes ouest $5^{\circ} 42^{\prime}$ $15^{\prime \prime}$ et $5^{\circ} 46^{\prime} 17^{\prime \prime}$ (Figure 1). Elle a été créée par l'arrêté n ${ }^{\circ} 1019$ du 27 mars 1939. La FCL couvre une superficie de 3982,99 ha. Elle se caractérise par un climat de type subéquatorial à 4 saisons, avec de forte variabilité climatique (Kassin et al., 2008).

La moyenne pluviométrique interannuelle enregistrée en 30 ans (19782007) est de $1395 \mathrm{~mm}$ selon les sources agroclimatiques de la station du Centre National de Recherche Agronomiques (CNRA) à Gagnoa, chef-lieu de région (Kassin et al., 2008). La température moyenne annuelle varie entre 26 et $28^{\circ} \mathrm{C}$. La FCL appartient au secteur Mésophile du domaine Guinéen (Guillaumet \& Adjanohoun, 1971) où la végétation est caractérisée par les forêts semidécidues à Celtis spp. et Triplochiton scleroxylon (Guillaumet \& Adjanohoun, 1971). La végétation actuelle de la FC est caractérisée par une anthropisation aiguë. Les formations dominantes actuelles sont les jachères et les plantations agricoles (OIBT, 2004). On y note aussi la présence de plantations forestières réalisées par la SODEFOR (Société de développement des Forêts) avec des espèces comme Terminalia superba Engl. \& Diels, Tectona grandis L.f., Cedrela odorata L., Gmelina arborea Roxb., Triplochiton scleroxylon K.Schum, Terminalia ivorensis A.Chev.

La population est constituée d'autochtones (Gagou ou Gban), d'allochtones ivoiriens (Baoulés, Malinkés et Sénoufos, etc.) et non ivoiriens (Burkinabé et les Maliens). L'agriculture, l'élevage, la chasse et la pêche sont les principales activités économiques du département. Les prélèvements des produits forestiers concernent les plantes médicinales, les bois de chauffe et les bois de service pour la construction d'habitats. 


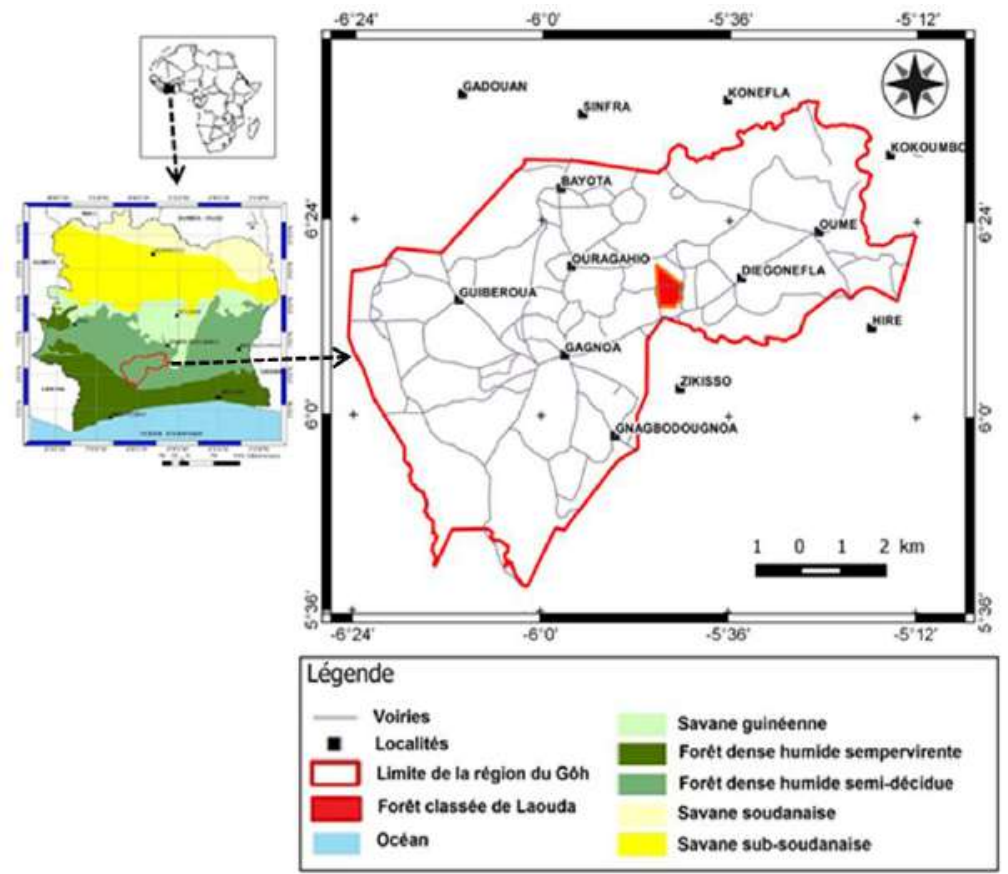

Figure 6. Situation géographique de la FCL

\subsection{Matériel}

Cette étude a nécessité l'utilisation de matériel biologique et matériel technique. Le matériel biologique est constitué de spécimens végétaux récoltés sous forme d'herbier. Le matériel technique est composé de données images satellitaires et de logiciels. Il s'agit des données images satellitaires à haute résolution, téléchargées sur le site internet "Earthexplorer (http://earthexplorer.usgs.gov). Ces images multi-bandes de la scène 197-056 sont celles de Landsat TM du 16 janvier 1986 et Landsat 8/OLI du 11 avril 2017, couvrant la forêt classée. Elles ont été appuyées de sources cartographiques dont la carte de végétation de la forêt classée de Laouda (1/30000) réalisée par le Centre de Gestion de la SODEFOR de Gagnoa (SODEFOR, 2014). Les logiciels ENVI 5.1 et QGIS (extension MOLUSCE) ont été respectivement utilisés pour les traitements numériques des images, la réalisation des cartes et l'analyse des modèles spatiaux. Le GPS (Global Positioning System) a été utilisé pour la prise des coordonnées géographiques des points d'échantillonnage et des parcelles d'entrainements.

Le matériel botanique est constitué d'un rouleau de fil sisal, un ruban de $50 \mathrm{~m}$ et des piquets, pour délimiter les parcelles sur le terrain. Des rubans gradués de $1 \mathrm{~m}$ ont été utilisées, pour la mesure des diamètres $(\geq 5 \mathrm{~cm})$ à hauteur de poitrine (DBH, diameter at breast height) des ligneux ; des sachets plastiques, pour transporter les spécimens récoltés ; des presses, pour sécher les échantillons récoltés et des fiches de relevé de végétation pour noter les 
noms des espèces et les informations utiles (lieu et date de récolte, coordonnées géographiques de la parcelle).

\subsection{Méthodes}

\subsubsection{Caractérisation de la végétation de la forêt classée de Laouda}

\subsubsection{Caractérisation physionomique de la végétation}

La caractérisation physionomique de la végétation a consisté à mettre en place au hasard à l'intérieur des sites visités des parcelles de $400 \mathrm{~m}^{2}(20 \mathrm{~m}$ x $20 \mathrm{~m}$ ). Une telle surface est appropriée à un inventaire biologique rapide (Chevalier et al., 2010; Koffi, 2016). La végétation en chacun des points retenus a été décrite visuellement à partir de critères physionomiques (Aubréville, 1956; Trochain, 1957), à savoir la structure horizontale et les espèces végétales dominantes.

Concernant le type de végétation, la nature a été précisée au niveau de chaque parcelle. Dans chaque parcelle, les circonférences des ligneux à hauteur de poitrine, $\mathrm{DBH} \geq 5 \mathrm{~cm}$, ont été déterminées à $1,3 \mathrm{~m}$ au-dessus du sol. Pour les espèces à DBH inférieur à $5 \mathrm{~cm}$, on ne note que leur présence pour établir la liste floristique de la zone d'étude. A l'intérieur de chaque parcelle de $400 \mathrm{~m}^{2}$, nous avons installé des sous parcelles de $100 \mathrm{~m}^{2}(10 \mathrm{~m} \times$ $10 \mathrm{~m}$ ), afin de recenser plus d'espèces et d'évaluer la densité des espèces dans les différents formations végétales (Adou Yao \& N'Guessan, 2005; Koffi, 2016; Kouadio, 2006). Le traitement des données collectées sur le terrain a permis d'analyser la structure horizontale des peuplements par le calcul de la densité de ligneux (D), de l'aire basale de tige (AB) (Dibi et al., 2008b; Kouadio, 2006).

La densité de ligneux "D" permet de décrire l'état démographique des espèces ligneuses de la végétation. Elle a été calculée à travers la formule suivante :

$$
\mathbf{D}=\mathbf{N} / \mathbf{S}
$$

$N$, le nombre de tige dans l'ensemble des placettes de la formation végétale considérés et $S$, la surface totale de la placette en hectare.

L'aire basale de tiges "AB" traduit le recouvrement au sol des espèces ligneuses et est déterminé par la formule suivante : $\mathbf{A B}=\left(\mathbf{d}^{2} \times \boldsymbol{\pi}\right) / \mathbf{4}$ $d$, le diamètre de la tige et $\pi=3,14$.

Ces indices ont été calculés pour les forêts denses, les forêts secondaires et les jachères anciennes. Pour que ces indices soient comparables, 5 placettes par type de végétation, soit au total 15 placettes ont servi de base aux différents calculs. La comparaison des indices a été effectuée par le test $t$ de Student, après l'Anova à 5\%. 


\subsubsection{Caractérisation cartographique de l'occupation du sol}

La caractérisation cartographique de l'occupation du sol a combiné des techniques de prétraitements et traitements d'images satellitaires. Le prétraitement d'image a consister à faire des corrections radiométrique et atmosphérique pour réduire les effets perturbateurs de l'atmosphère, particulièrement chargée de nuage et de poussière en période de l'harmattan (Song et al., 2001). Puis, à découper une fenêtre de 305 colonnes sur 419 lignes centrée sur la forêt classée. Cette portion d'image a servi à la production de la carte de l'occupation du sol. Plusieurs techniques de traitements notamment l'indice de la différence normalisée de végétation (NDVI), les compositions colorées 5R-4V-1B correspondant respectivement aux bandes (TM 5-4-1 et OLI 6-5-2) et la classification non supervisée par l'algorithme des «Isodata » (Iterative Self Organizing Data Analysis Technic) ont été réalisées. L'analyse combinée des bandes multispectrales et des néo-canaux issus de ces traitements a permis de rehausser le contraste entre les bandes et de caractériser l'occupation de sol à la suite de la mission terrain. Ainsi, les unités thématiques suivantes ont été identifiées. Ce sont les forêts denses, les forêts secondaires, les plantations forestières, les jachères (anciennes et récentes), les cultures (pérennes et vivrières), les mosaïques cultures-jachères, les mosaïques cultures-forêts, les affleurements rocheux, les sols nus, les habitations, les bas-fonds (terrain bas généralement marécageux, ayant un couvert arbustif sur les bords de bas-fonds, dominé par les graminées à l'intérieur et abrite aussi les cultures). Sur la base de ces différents types d'occupation du sol, 160 parcelles dites « vérité terrain » ont été sélectionnées et visitées.

La cartographie de l'occupation du sol a été réalisée par la méthode de classification dirigée sur la composition coloré $5 \mathrm{R}-4 \mathrm{~V}-1 \mathrm{~B}$ par l'algorithme des réseaux de neurones multicouche à retro-propagation d'erreurs. Cet algorithme effectue une classification non paramétrique (ne nécessite pas l'établissement d'un modèle statistique des classes), le rendant ainsi performant (Hosni, 2002). Les réseaux de neurones utilisés ont été implémentés dans le logiciel ENVI 5.1 grâce au module Neural Net classification. Les paramètres définis dans cette étude sont les mêmes que ceux de Jofack et al. (2016) et de Douffi et al. (2019). Les itérations raisonnables de 1000 , un momentum de 0,88 , un seuil d'arrêt de 0,15 , un taux d'apprentissage fixé à 0,03 , une fonction de transfert sigmoïde et une seule couche cachée ont été choisies afin d'obtenir des cartes d'occupation de sol à l'aide de 85 parcelles d'entraînement (Jofack et al., 2016). L'évaluation de la précision des cartes a été réalisée par la comparaison de l'image classifiée avec les données de terrain. Cette comparaison est basée sur la matrice de confusion, élaborée à partir de 84 autres parcelles dites parcelles de contrôle, 
qui indique les commodités et les incommodités entre les ensembles de données (Dibi et al., 2008a).

La carte d'occupation du sol produite a été par la suite simplifiée par le regroupement des classes (Dibi et al., 2008a), afin de facilités l'analyse des résultats :

- la classe culture est issue des cultures pérennes, des cultures vivrières, des mosaïques cultures-jachères et des mosaïques cultures-forêts ;

- la classe forêt secondaire est issue des plantations forestières et des forêts dégradées ;

- La classe sol nu regroupe les affleurements rocheux et toutes les surfaces dénudées ;

- La classe jachère regroupe les jachères anciennes et les jachères récentes.

\subsubsection{Dynamique et transformation spatio-temporelle de l'occupation du sol de 1986 et 2017}

\subsubsection{Matrice de transition et indices de structure spatiale}

La matrice de transition et les indices de structure spatiale ont permis de quantifier les transformations de l'occupation du sol opérées entre 1986 et 2017. La matrice de transition entre deux états ( $\mathrm{t}_{0}$ et $\left.\mathrm{t}_{1}\right)$ est obtenue à partir de la superposition des deux cartes grâce à l'extension MOLUSCE du logiciel QGIS. Elle correspond à une matrice carrée décrivant, les changements d'état des éléments d'un système pendant une période donnée (Schlaepfer, 2002). Les cellules de la matrice contiennent la valeur d'une variable ayant passé d'une classe initiale $i$ à une classe finale $j$ pendant la période allant de $t_{0}$ à $t_{1}$. Les valeurs des colonnes et des lignes représentent des proportions des aires occupées par chaque classe d'occupation du sol au temps correspondant. Ainsi, les colonnes de la matrice indiquent les états d'occupations des sols en 2017 et les lignes correspondent aux états en 1986.

La suite de l'analyse a consisté au calcul d'indices de structure spatiale à savoir la proportion d'occupation des classes (PC), l'indice de dominance (D) et l'indice de forme (IF). Ces indices sont souvent un indicateur de l'impact de l'activité humaine sur la morphologie du paysage (Barima et al., 2009; Krummel et al., 1987; Lampin-Maillet et al., 2010; Toko et al., 2012).

La proportion d'occupation des classes (PC) mesure la proportion du paysage occupée par les différents types d'occupation du sol: $\mathbf{P C}=$ $\left(\sum \boldsymbol{a}_{\boldsymbol{i j}} / \boldsymbol{a}\right) * \mathbf{1 0 0}$

Avec $a_{i j}$ l'aire de la tache $i$ de la classe $j$ et a l'aire totale.

L'indice de dominance $(\mathrm{Dj})$ est le rapport de l'aire de la plus grande tâche de la classe et l'aire totale de la classe $: \mathbf{D}_{\mathbf{J}}=\left(\mathbf{a}_{\mathbf{m a x}, \mathbf{j}} / \mathbf{a}_{\mathbf{j}}\right) * \mathbf{1 0 0}$ 
Avec $a_{\operatorname{max.j}}$ l'aire de la plus grande tache de la classe $j$ et $a_{j}$, l'aire totale de la classe $j$. Cet indice $\left(\mathbf{D}_{\mathbf{J}}\right)$ qui prend des valeurs entre 0 et 100 . Il permet de déterminer le niveau de fragmentation de la classe. Plus la valeur de la dominance de la plus grande tâche tend vers 100, moins la classe est fragmentée et lorsque cette valeur tend vers 0 la classe est fragmentée (McGarigal \& Cushman, 2002; Toko et al., 2012).

L'indice de forme pour une classe d'occupation du sol est le rapport du périmètre $(\mathrm{P})$ et de l'aire $(\mathrm{a})$ de la classe considérée selon l'équation : IF = $\boldsymbol{P}_{\boldsymbol{i j}}^{2} / \boldsymbol{a}_{\boldsymbol{i j}}$

Avec, $\mathrm{P}_{\mathrm{ij} \text { et }} \mathrm{a}_{\mathrm{ij}}$, respectivement le périmètre et l'aire de la tache $\mathrm{i}$ de la classe $\mathrm{j}$.

L'indice de forme prend des valeurs élevées pour les objets naturels qui présentent des formes complexes. Ces valeurs décroîtrons dans le cas des objets modifiés par l'homme qui ont des formes régulières (carré, rectangle) (Bamba et al., 2010). En plus de ces indices, les variations des superficies des classes d'occupation du sol ont été déterminées à partir de leur taux d'évolution : $\mathbf{T}_{\mathbf{v}}=\left(\left(\mathbf{S}_{\mathrm{fj}}-\mathbf{S}_{\mathrm{ij}}\right) / \mathbf{S}_{\mathrm{ij}}\right) * \mathbf{1 0 0}$

Où $T_{v}$, le taux d'évolution, $S_{f j}$ la superficie finale de la classe $j$ et $S_{i j}$, la superficie initiale de la classe $\mathrm{j}$.

\subsubsection{Processus de transformation spatiale}

Les processus de transformation spatiale sont nécessaires pour la description de la configuration paysagère (Bamba, 2010; Bogaert et al., 2004). C'est une approche complémentaire (Figure 2) pour analyser la dynamique structurelle du paysage. Elle est basée sur l'évolution de l'aire (a), du périmètre ( $\mathrm{p}$ ) et du nombre de taches (n) entre les temps $\mathrm{T}_{0}$ et $\mathrm{T}_{1}$ en comparant les valeurs de $\mathrm{a}_{0}, \mathrm{p}_{0}$ et $\mathrm{n}_{0}$ à $\mathrm{T}_{0}$ avec, respectivement, $\mathrm{a}_{1}$, $\mathrm{p}_{1}$ et $\mathrm{n}_{1} \mathrm{a} \mathrm{T}_{1}$ (Bamba, 2010; Bogaert et al., 2004). Ce processus met en exergue le type de transformation dont la dégradation, l'apparition et la neutralité (Tableau 1). Pour vérifier la fiabilité de la modélisation de transformation effectuée, la valeur $t$ est comparée à une valeur $t$ observée $\left(\mathrm{t}_{\mathrm{obs}}=\mathrm{a}_{1} / \mathrm{a}_{0}\right)$ au seuil critique de probabilité $(t=0,5)$ conformément à (Barima et al., 2009). 


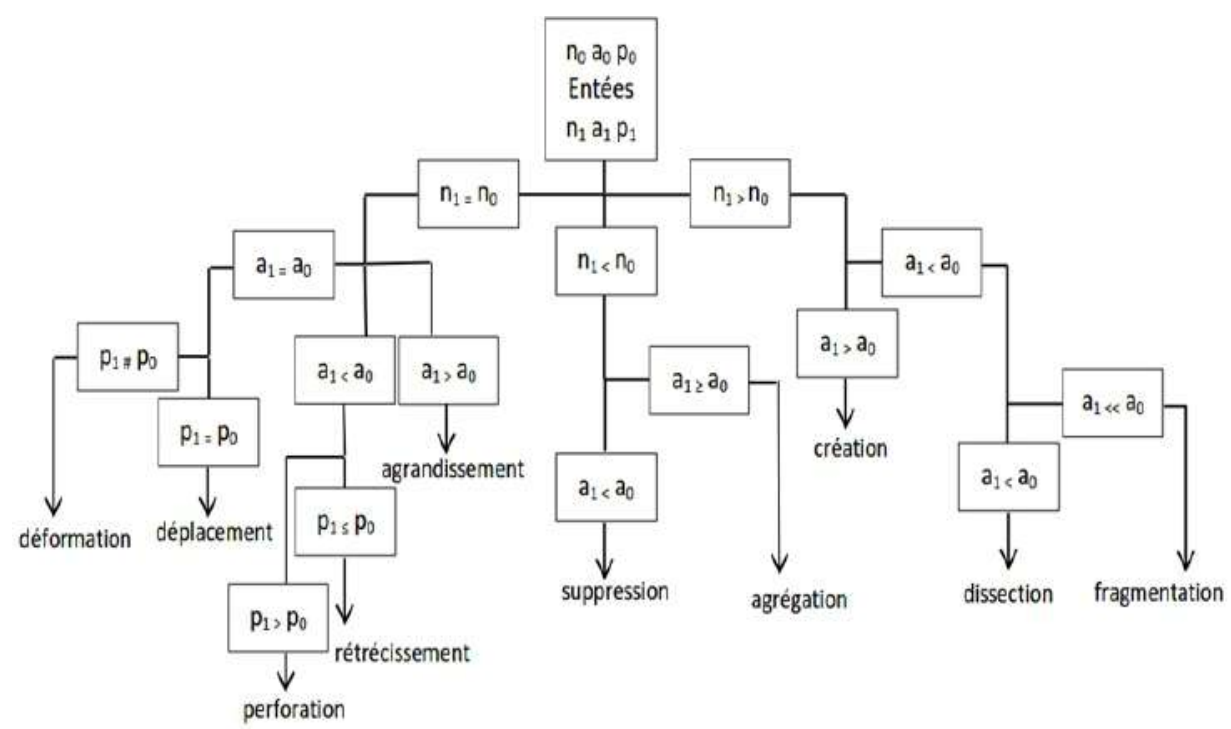

Figure 7. Arbre de décision pour l'identification des processus de transformation spatiale. $\left(\mathrm{a}_{0}, \mathrm{p}_{0}\right.$ et $\mathrm{n}_{0}$, respectivement à l'aire, au périmètre et au nombre de taches avant la transformation, et $\mathrm{a}_{1}, \mathrm{p}_{1}$ et $\mathrm{n}_{1}$ après le changement (Bogaert et al., 2004).

Tableau II. Définitions et diagrammes des dix processus spatiaux de la transformation des terres (Bogaert et al., 2004).

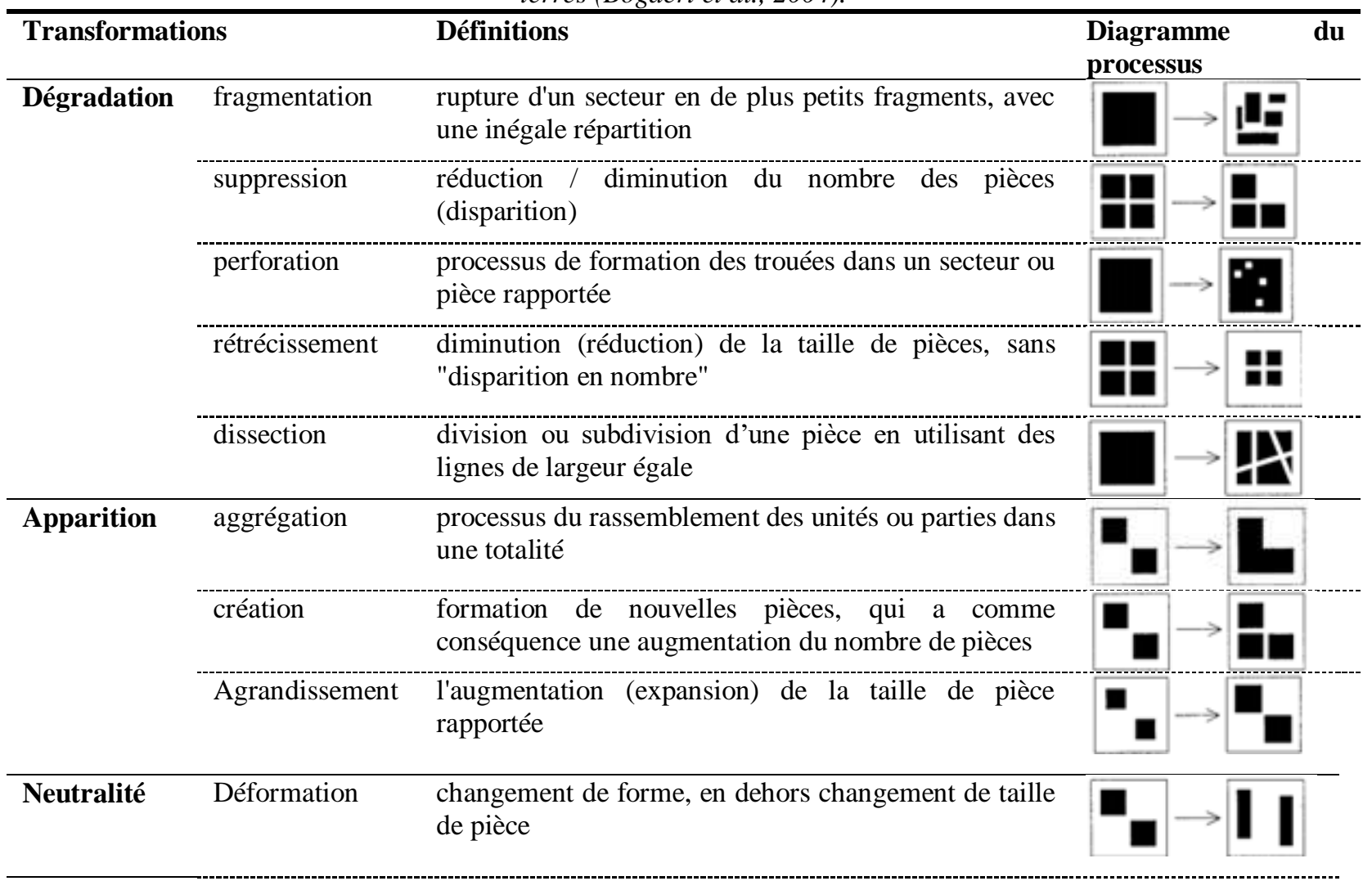




\section{Résultats}

\subsection{Physionomie et cartographie de végétation de la forêt classée de} Laouda.

\subsubsection{Physionomie de la végétation de la forêt classée de Laouda.}

\subsubsection{Typologie de la végétation de la forêt classée de Laouda.}

Les formations végétales visitées sont des forêts et des jachères. Les forêts sont de trois types (Figure 3). Les forêts de type 1 sont des forêts denses qui sont soit des forêts denses à canopée fermée soit des forêts denses ouvertes. Ces forêts denses se rencontrent autour des affleurements rocheux et dans les zones de terre ferme. Les espèces dominantes sont Alstonia boonei De wild., Celtis philippensis Blanco, Cola caricifolia (G.Don) K.Schum., Funtumia elastica (Preuss) Stapf, Hibiscus tiliaceus L, Musanga cecropioides R.Br. ex Tedlie, Sterculia rhinopetala k.Schum. et Trichilia heudelotii Planch. ex Oliv.

Les forêts de type 2 présentent un aspect très dégradé. Ce sont des forêts secondaires issues de la dégradation des forêts denses ou des forêts en reconstitution qui colonisent les affleurements rocheux de la forêt. On y retrouve fréquemment les espèces telles que Bombax buonopozense P.Beauv., Nesogordonia papaverifera (A.Chev) Capuron ex N. Hallé, Newbouldia laevis (P.Beauv) Seem., Ricinodendron heudelotii (Baill.) Heckel et Sterculia tragacantha Lindl.

Les forêts de type 3 sont des plantations forestières réalisées par la SODEFOR avec les espèces comme Terminalia ivorensis, Tectona grandis, Gmelina arborea et Triplochiton scleroxylon. On note aussi la présence de Blighia welwitschii (Hiern) Radlk., Celtis Zenkeri Engl. et Trichilia monadelpha (Thonn) J.J.de Wilde. La structure est comparable à celle des forêts secondaires.

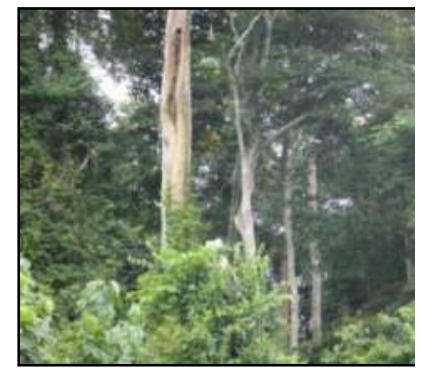

a. Forêt de type 1

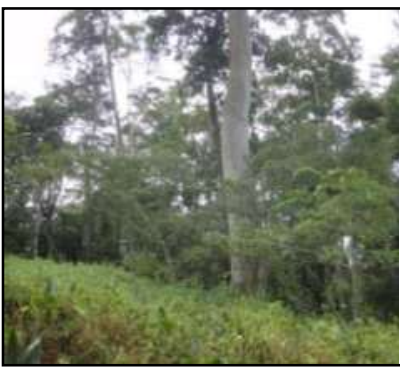

b. Forêt de type 2

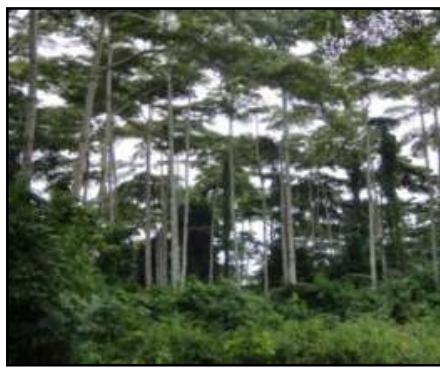

c. Forêt de type 3

Figure 8. Formations forestières de la forêt classée de Laouda

La jachère est une formation qui découle de l'abandon des plantations. Deux types de jachères ont été observés en fonction de la densité de ligneux. On les retrouve un peu partout dans la forêt de Laouda. La jachère ancienne 
(Figure 4a) présente une strate ligneuse relativement dense par endroit. La strate inférieure est composée de fourrés d'espèces héliophiles mélangées à une végétation d'herbes et d'arbustes favorisée par la pénétration de la lumière jusqu'au sol. Les espèces couramment rencontrées sont Albizia zygia (DC.) J.F.Macbr., Alchornea cordifolia (Schumach. \& Thonn.) Müll.Arg., Cnestis ferruginea Vahl ex DC., Ficus exasperata Vahl et Griffonia simplicifolia (DC.) Baill. La jachère récente (Figure 4b) est plus pauvre en ligneux. Il s'agit de parcelles exploitées il y a 1 ou 2 ans pour les cultures vivrières. La strate ligneuse de diamètre $\geq 5 \mathrm{~cm}$ est quasiment inexistante. Le tapis herbacé est dominé par Chromolaena odorata (L.) R.M.King \& H.Rob. On note également la présence d'autres espèces telles que Panicum maximum Jacq. et Mimosa pudica L.

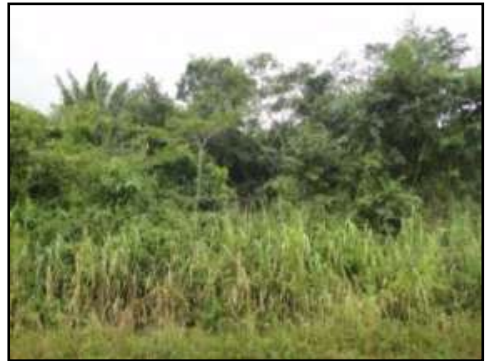

a. Jachère ancienne

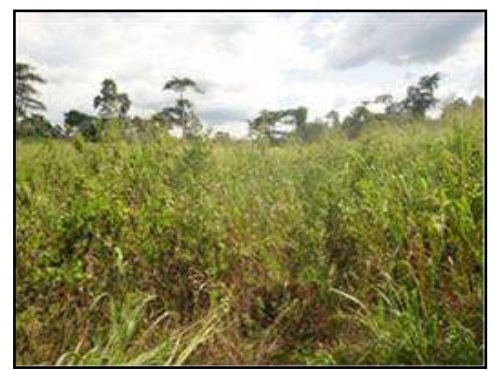

b. Jachère récente

Figure 9. Jachères de la forêt classée de Laouda

\subsubsection{Structure de la végétation : densité et aire basale}

L'analyse de la structure de la végétation montre que la densité des tiges et l'aire basale sont variables selon les types de végétation (Figure 5 a et b). Pour la densité, la comparaison des biotopes montre que la jachère enregistre la plus faible densité avec une moyenne de 904,16 tiges/ha. La forêt dense à la densité la plus élevée (1608,33 tiges/ha). Malgré cela, la différence entre les densités moyennes, n'est pas significative $(p>0,05)$.

Pour ce qui concerne l'aire basale, avec une moyenne égale à 4,3 $\mathrm{m}^{2} /$ ha, la forêt dense possède la valeur la plus élevée. Elle est suivie de la forêt secondaire avec une moyenne de $3,64 \mathrm{~m}^{2} /$ ha. La jachère ancienne présente la plus faible valeur $\left(1,06 \mathrm{~m}^{2} / \mathrm{ha}\right)$. Il y a une différence significative entre les aires basales de la forêt dense et de la jachère (Test $\mathrm{t}$ de Student, $\mathrm{t}=5,922 ; \mathrm{p}=$ 0,001). Par contre, la différence des forêts est moins perceptible au niveau des aires basales. La comparaison de ce paramètre de la structure horizontale, par le test d'Anova au seuil de 5\%, indiquent qu'ils sont statistiquement proches. 


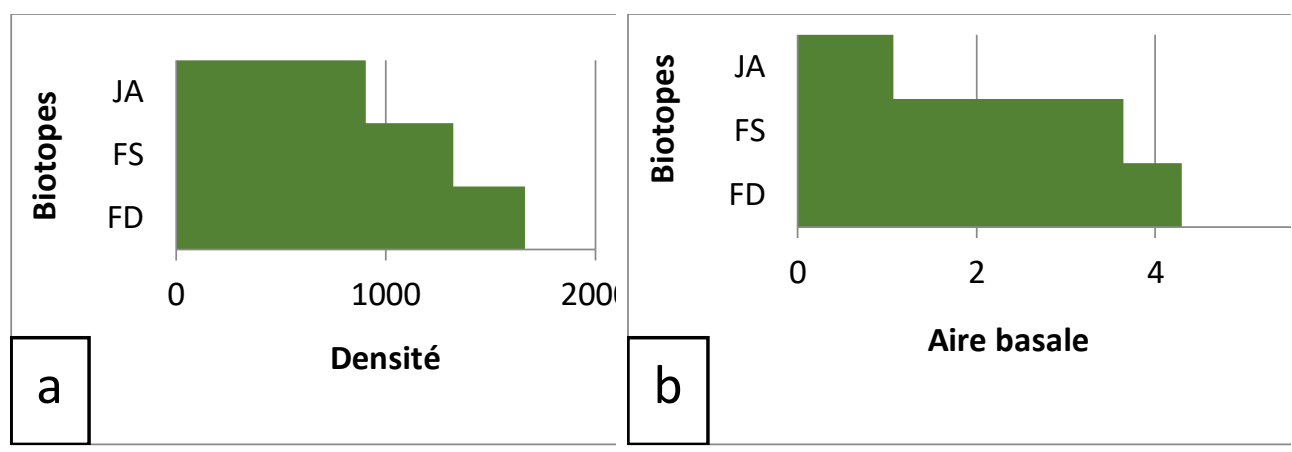

Figure 10. Densités de tiges (a) et aires basales (b) des différentes biotopes de la FCL (FD = forêt dense, $F S=$ forêt secondaire, $J A=$ jachère ancienne)

\subsubsection{Occupation du sol de la forêt classée de Laouda en 2017 et en 1986}

Les matrices de confusion indiquent que les taux de classification globale sont de 85,55\% et 92,72\%, respectivement pour les images de 1986 et 2017 (Tableaux II et III). Ces tableaux affichent dans la diagonale le pourcentage de pixels bien classés et hors diagonale le pourcentage de pixels mal classés. L'analyse de ces données montre que la classe de jachère présente de fortes confusions (12 à $36 \%$ ) avec la classe de culture d'où le faible pourcentage de pixel de jachère bien classé (47 à $86 \%$ ).

En 1986, la classe de bas-fond présente un faible pourcentage de pixels bien classés $(47,58 \%)$ à cause des confusions avec la classe jachère $(34,68 \%)$ et la classe de culture $(16,94 \%)$. La classe de forêt dense présente également une forte confusion (17,34\%) avec la classe de forêt secondaire en 2017.

Tableau III. Matrice de confusion de la classification de l'image Landsat TM de 1986. Précision globale $=85,55 \%$, Coefficient de kappa $=0,81$

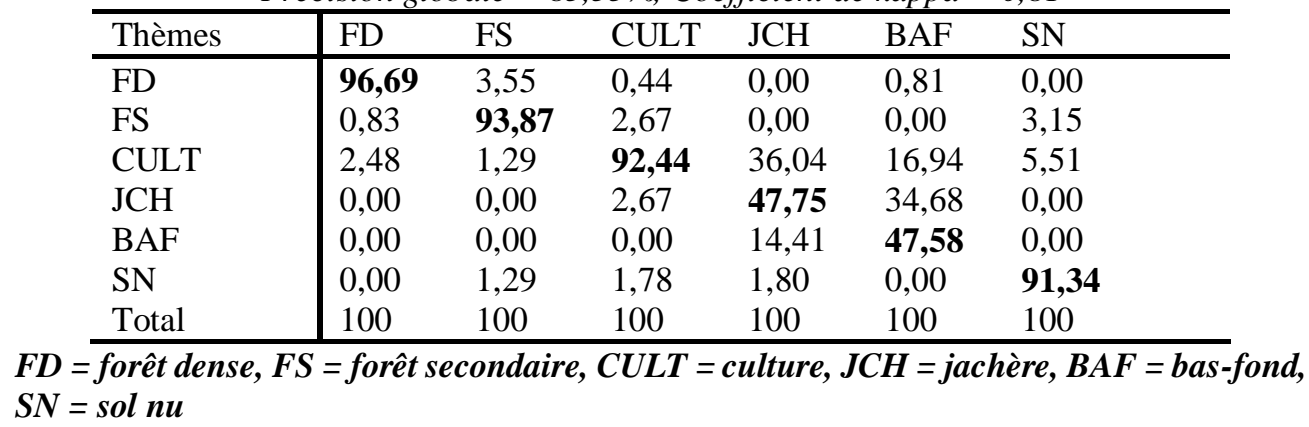


Tableau IV. Matrice de confusion de la classification de l'image Landsat Oli 2017.

Précision global $=92,72 \%$, Coefficient de kappa $=0,90$

\begin{tabular}{l|llllll}
\hline Thèmes & FD & FS & CULT & JCH & BAF & SN \\
\hline FD & $\mathbf{8 2 , 4 6}$ & 1,79 & 0,00 & 0,91 & 0,00 & 0,00 \\
FS & 17,54 & $\mathbf{9 3 , 7 5}$ & 1,16 & 0,00 & 4,31 & 0,00 \\
CULT & 0,00 & 4,46 & $\mathbf{9 3 , 9 1}$ & 12,73 & 0,86 & 0,00 \\
JCH & 0,00 & 0,00 & 4,93 & $\mathbf{8 6 , 3 6}$ & 0,00 & 0,61 \\
BAF & 0,00 & 0,00 & 0,00 & 0,00 & $\mathbf{9 4 , 8 3}$ & 0,00 \\
SN & 0,00 & 0,00 & 0,00 & 0,00 & 0,00 & $\mathbf{9 9 , 3 9}$ \\
Total & 100 & 100 & 100 & 100 & 100 & 100 \\
\hline
\end{tabular}

$F D=$ forêt dense, $F S=$ forêt secondaire, $C U L T=$ culture, $J C H=$ jachère, $B A F=$ bas-fond, $\mathrm{SN}=$ sol $\mathrm{nu}$

L'occupation du sol de la forêt classée de Laouda en 1986 et en 2017 est illustrée par la figure 7. Ces cartes sont issues de la classification supervisée par le réseau de neurone des images Landsat 5 de 1986 et Landsat OLI de 2017 avec des coefficients de kappa respectifs de 0,81 et 0,90 (Tableaux II et III). Ces valeurs de coefficient de kappa obtenues permettent de conclure que les scores de ces classifications sont excellents.

En 1986, la FCL était dominée par les formations forestières. Elles étaient bien disséminées à l'intérieur du site (Figure 7a). Pour la plupart, elles sont localisées au Centre-est et au Sud-est. On note l'existence de cultures et de jachères à la périphérie des ilots de forêt, des affleurements rocheux et le long des cours d'eau à l'intérieur de la FCL. En 2017, toutes les unités d'occupation du sol observé en 1986 sont également présentes (Figure 7b). Mais, Les surfaces de forêts denses ont diminuées de moitié (Tableau IV). Elles sont représentées par de petites parcelles parsemées dans la FCL. Par contre, les parcelles de cultures et de jachères ont augmenté de surface (Tableau IV). On les retrouve partout à l'intérieur de la forêt classée.

Les statistiques des unités de l'occupation du sol de 1986 et de 2017 (Tableau IV) montrent que les zones de culture et de jachère ont remplacé les forêts au cours de la période étudiée. Les superficies de forêt dense de 41,35 $\%$ en 1986 ont été ramenées à 22,02\% en 2017 et les superficies de forêt secondaire sont passées de $28,85 \%$ en 1986 à 9,62 \% en 2017. Pendant ce temps, les surfaces des cultures et des jachères ont considérablement augmenté, passant de 23,88 \% à 55,99 pour les cultures et les jachères de 1,44 $\%$ à $8,80 \%$. Par ailleurs, les sols nus et les bas-fonds ont faiblement baissés. 

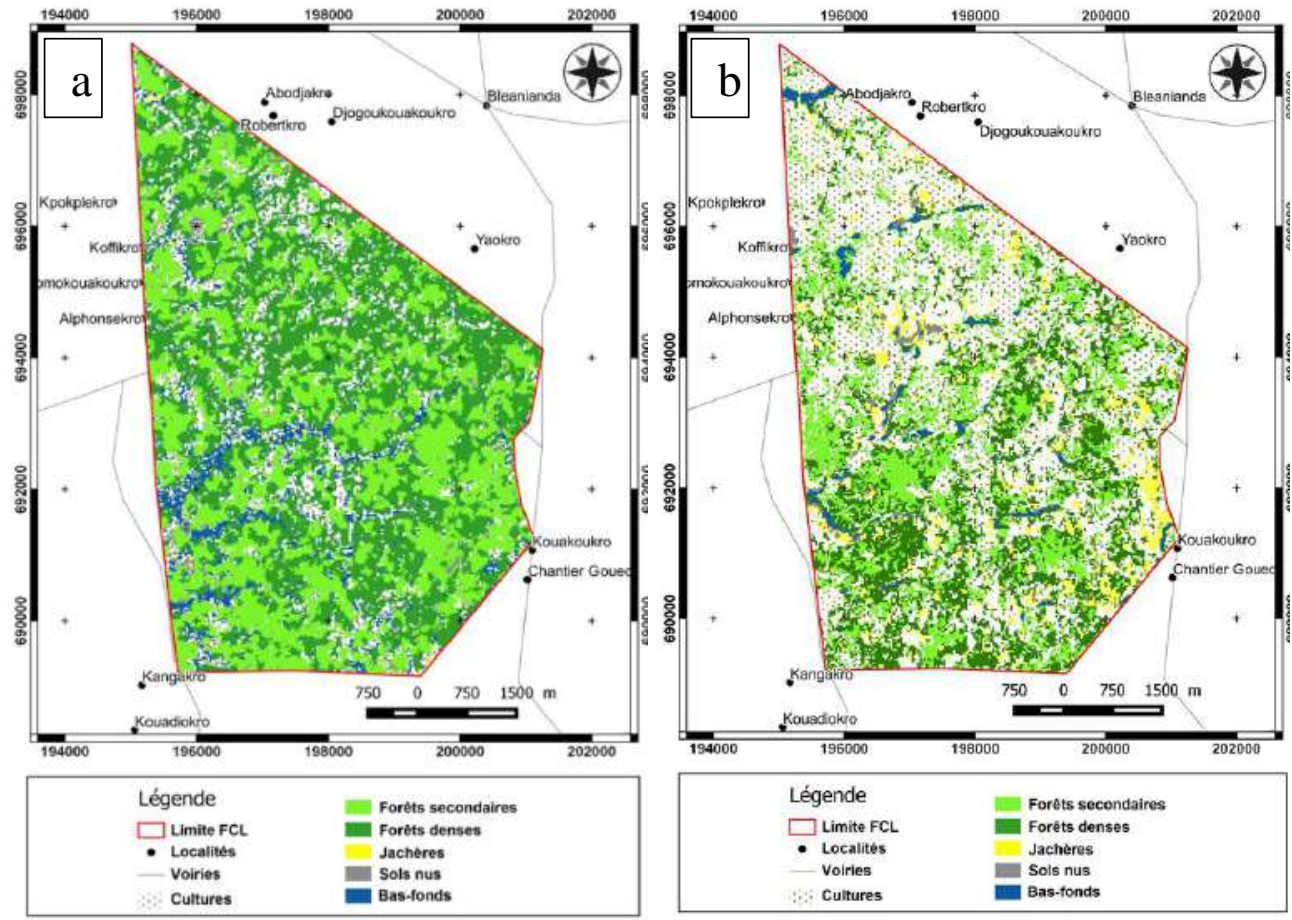

Figure 7. Cartes de l'occupation du sol en 1986 (a) et en 2017 (b)

Tableau V. Statistiques des unités de l'occupation du sol de 1986 et de 2017.

\begin{tabular}{lllll}
\hline Thèmes & $\mathbf{1 9 8 6}$ & \multicolumn{3}{c}{$\mathbf{2 0 1 7}$} \\
\cline { 2 - 5 } & Surface (ha) & Proportion (\%) & Surface (ha) & Proportion (\%) \\
\hline Forêt dense & 1648,20 & 41,35 & 877,58 & 22,02 \\
Forêt secondaire & 1150,06 & 28,85 & 383,6 & 9,62 \\
Jachères & 57,49 & 1,44 & 350,65 & 8,80 \\
Sols nus & 83,31 & 2,09 & 58,31 & 1,46 \\
Bas-fonds & 92,07 & 2,31 & 80,87 & 2,03 \\
Cultures & 951,86 & 23,88 & 2231,98 & 55,99 \\
Total & 3982,99 & 100 & 3982,99 & 100 \\
\hline
\end{tabular}

3.2. Transfert et dynamique de l'occupation du paysage de la forêt classée de Laouda

3.2.1. Transfert de l'occupation du paysage de la forêt classée de Laouda

Les transferts opérés entre les différentes classes d'occupation du paysage entre 1986 et 2017 de la forêt de Laouda sont illustrées par le tableau V. De façon générale, ce tableau montre un faible indice de stabilité globale de $0,33(<0,50)$. Cela montre une importante transformation du paysage entre 1986 et 2017. En effet, $19,17 \%, 7,45 \%$ et $17,75 \%$ du paysage ont été convertis respectivement en sols nus, en jachères et en cultures. Seuls 1,58 \%, $1,58 \%$ et $6,33 \%$ du paysage occupés respectivement par les sols nus, les 
jachères et les cultures ont connu une dynamique de densification. Les cultures et les jachères ont constitué les classes les plus stables avec des taux respectifs de $5,88 \%$ et de $12,20 \%$. Tandis que les forêts secondaires et les bas-fonds présentent les plus faibles stabilités respectives de $0,94 \%$ et $0,20 \%$. Les transferts entre les différentes classes sont plus importants des forêts aux cultures et des bas-fonds aux jachères. Sur les 32,30 \% du paysage occupés par les cultures en 2017, 12,02 \% étaient de la forêt (forêt dense et forêt secondaire) en 1986. En ce concerne les 32,60\% du paysage occupés par les jachères en 2017, 13,02 \% sont issues des bas-fonds en 1986. La forêt dense a subit des phénomènes d'ouvertures à des degrés divers vers les forêts secondaires $(1,63 \%)$, les bas-fonds $(1,46 \%)$, les sols nus $(1,26 \%)$, les jachères $(1,51 \%)$ et les cultures $(1,33 \%)$.

Tableau VI. Matrice de transition de l'occupation du paysage entre 1986 et 2017.

\begin{tabular}{llllllll}
\hline $\begin{array}{l}2017 \\
1986\end{array}$ & FD & FS & BAF & SN & JCH & CULT & Totaux \\
\hline FD & $\mathbf{1 , 2 7}$ & 0,86 & 0,21 & 1,58 & 1,58 & 6,33 & 11,90 \\
FS & 1,63 & $\mathbf{0 , 9 4}$ & 0,22 & 0,67 & 0,67 & 5,69 & 10,20 \\
BAF & 1,46 & 1,21 & $\mathbf{0 , 2 0}$ & 13,02 & 13,02 & 4,28 & 24,78 \\
SN & 1,26 & 0,69 & 0,30 & $\mathbf{1 , 2 4}$ & 1,24 & 5,82 & 13,43 \\
JCH & 1,51 & 0,98 & 0,22 & 12,20 & $\mathbf{1 2 , 2 0}$ & 4,27 & 25,15 \\
CULT & 1,33 & 0,89 & 0,21 & 3,86 & 3,86 & $\mathbf{5 , 8 8}$ & 14,55 \\
Totaux & 8,49 & 5,60 & 1,39 & 32,60 & 32,60 & 32,30 & 100 \\
Indice de stabilité : 0,33 & & & & & \\
\hline
\end{tabular}

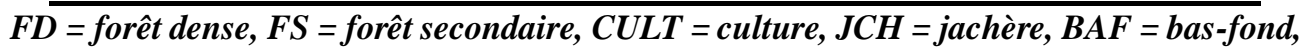
$\mathrm{SN}=\operatorname{sol} \mathrm{nu}$

\subsubsection{Processus de transformation et dynamique de l'occupation du paysage}

Les Tableaux VI et VII montrent la dynamique et le processus de transformation de l'occupation du paysage entre 1986 et 2017. Au cours de cette période, les forêts ont connu des processus de dégradation. Il s'agit, au niveau des forêts denses, de la dissection caractérisée par une augmentation du nombre de taches (363 à 1166) et une diminution de l'aire totale des taches (1648,2 ha à 877,58 ha). Une diminution de la valeur de l'indice de dominance de la plus grande tâche a été également constatée. Pour les forêts secondaires, le nombre de tâche et l'indice de dominance de la plus grande tâche sont multipliés par environ 4. L'aire totale des tâches diminue de 1150,06 ha à 383,6 ha. Il y a donc une fragmentation des forêts secondaires. Les bas-fonds ont également connu des processus de dégradation caractérisés par une augmentation de l'indice de dominance de la plus grande tâche $(6,74$ à 12,35) et une diminution du nombre de tache (280 à 204), ainsi que de la surface totale des tâches $(92,07$ ha à 80,87 ha). Ceci indique un processus de suppression avec $t_{\mathrm{obs}}=0,88$. 
En ce qui concerne les sols nus, L'évolution des indices indique une tendance à la dissection avec $\mathrm{t}_{\mathrm{obs}}=0,7$. En effet, nous observons une régression du nombre de tâches (307 à 159) et de l'aire totale $(83,31$ ha à 58,31 ha) des tâches entre 1986 et 2017. Contrairement à la tendance de régression de l'aire des tâches, la proportion qu'occupe la plus grande tache a connu une augmentation (5,08 à 7,25).

Par ailleurs, les jachères et cultures ont connu un processus d'apparition d'entités (artificialisation). Les jachères ont connu des processus de création avec une augmentation du nombre de tâche (403 à 650) et de l'indice de dominance de la plus grande tâche $(5,48$ à 8,23). Ces processus ont été accompagnés par une diminution du périmètre total $\left(8,69 \mathrm{~km}^{2}\right.$ à $\left.6,82 \mathrm{~km}^{2}\right)$ et de la surface totale des tâches (57,49 ha à 350,65 ha). Pour les cultures, les taches ont connu une régression de leur nombre (901 à 390) et de leur périmètre $\left(57,96 \mathrm{hm}^{2}\right.$ à $\left.65,98 \mathrm{~km}^{2}\right)$ d'où un processus d'agrégation. Cette agrégation des tâches de cultures est également perçue au niveau de la valeur de la dominance de la plus grande tâche qui enregistre la plus forte augmentation de la valeur de la dominance (13,32 à 62,89). L'évolution de l'indice des formes avec les classes a été constatée. Dans les classes où augmente le taux d'occupation du sol, l'indice de forme diminue. Au niveau des jachères, cet indice de forme passe de 1,31 à 0,13 , tandis que dans les cultures il est passé de 3,53 à 1,95. Les autres classes voient la valeur de cet indice augmenté ou se maintenir. Cependant, la valeur de cet indice est faible pour toutes les classes. Ce qui reflèterait une évolution des taches vers des formes de plus en plus régulières d'où une tendance à l'artificialisation.

Tableau VII. Indices de structure spatiale calculés en 1986 et 2017 pour chaque thème

\begin{tabular}{lllllllllll}
\hline & $\mathbf{n p}$ & \multicolumn{3}{c}{$\mathbf{P}(\mathrm{km})$} & $\mathbf{a}\left(\mathrm{km}^{2}\right)$ & \multicolumn{3}{c}{$\mathbf{D j}(\%)$} & \multicolumn{3}{c}{$\mathbf{I F}$} \\
\cline { 2 - 9 } Thèmes & 1986 & 2017 & 1986 & 2017 & 1986 & 2017 & 1986 & 2017 & 1986 & 2017 \\
\hline Forêts denses & 363 & 1166 & 40,17 & 55,88 & 1648,2 & 877,58 & 73,51 & 4,37 & 0,98 & 3,56 \\
Forêts secondaires & 249 & 1067 & 6,54 & 3,76 & 1150,06 & 383,6 & 7,41 & 26,11 & 0,04 & 0,04 \\
Jachères & 403 & 650 & 8,69 & 6,82 & 57,49 & 350,65 & 5,48 & 8,23 & 1,31 & 0,13 \\
Roches-sols nus & 307 & 159 & 58,94 & 49,28 & 83,31 & 58,31 & 5,08 & 7,25 & 41,70 & 41,64 \\
Bas-fonds & 280 & 204 & 5,49 & 23,51 & 92,07 & 80,87 & 6,74 & 12,35 & 0,33 & 6,83 \\
Cultures & 901 & 390 & 57,96 & 65,98 & 951,86 & 2231,98 & 13,32 & 62,89 & 3,53 & 1,95 \\
\hline
\end{tabular}

np = nombre de tâches de la classe, $P=$ périmètre total de la classe, a = aire totale de la classe, $\mathrm{DJ}=$ dominance de la plus grande tâche, IF = indice des formes. 
Tableau VIII. Processus de transformation spatiale des unités thématiques

\begin{tabular}{|c|c|c|c|c|}
\hline Thèmes & indices & Seuil critique 0,5 & Comparaison & Transformation \\
\hline \multirow{3}{*}{ Forêts denses } & $\mathrm{np}$ & $\mathrm{T}_{\mathrm{obs}}: 0,53<0,5$ & np2017 > np1986 & dissection \\
\hline & $\mathrm{a}$ & & a2017 < a1986 & \\
\hline & $\mathrm{p}$ & & p2017 > p1986 & \\
\hline \multirow{3}{*}{ Forêts secondaires } & np & $\mathrm{T}_{\text {obs }}: 0,33<0,5$ & np2017 > np1986 & fragmentation \\
\hline & $\mathrm{a}$ & & a2017 < a1986 & \\
\hline & $\mathrm{p}$ & & p2017<p1986 & \\
\hline \multirow{3}{*}{ Jachères } & $\mathrm{np}$ & $\mathrm{T}_{\mathrm{obs}}: 6,1>0,5$ & np2017 > np1986 & création \\
\hline & $\mathrm{a}$ & & a2017 > a1986 & \\
\hline & $\mathrm{p}$ & & p2017< p1986 & \\
\hline \multirow{3}{*}{ Sols nus } & $\mathrm{np}$ & $\mathrm{T}_{\mathrm{obs}}: 0,7>0,5$ & np2017 > np1986 & dissection \\
\hline & $\mathrm{a}$ & & a2017 < a1986 & \\
\hline & $\mathrm{p}$ & & p2017<p1986 & \\
\hline \multirow{3}{*}{ Bas-fonds } & np & $\mathrm{T}_{\text {obs }}: 0,88>0,5$ & np2017< np1986 & suppression \\
\hline & $\mathrm{a}$ & & a2017 < a1986 & \\
\hline & $\mathrm{p}$ & & p2017 > p1986 & \\
\hline \multirow{3}{*}{ Cultures } & np & $\mathrm{T}_{\text {obs }}: 2,34>0,5$ & np2017 < np1986 & agrégation \\
\hline & $\mathrm{a}$ & & a2017> a1986 & \\
\hline & $\mathrm{p}$ & & p2017 > p1986 & \\
\hline
\end{tabular}

\section{Discussion}

\subsection{Physionomie de la végétation}

Les espèces caractéristiques des formations forestières et des jachères sont celles des variantes de la forêt dense semi-décidue et des écosystèmes savanicoles. La présence des espèces caractéristiques des forêts semi-décidues et des savanes dans les jachères et dans les formations forestières, est la preuve d'une savanisation de la FCL. Cette situation est due à la pratique culturale non durable, elle-même provoquée par une pression démographique et la réduction du temps de jachère (Devineau, 1984). L'étude de la structure a permis de constater que globalement, les formations forestières et les jachères ont de faibles valeurs de densité (904,16 à 1608,33 tiges/ha) et d'aire basale (1,06 à 4,3 m²/ha). Ces faibles valeurs peuvent s'expliquer par le fait que dans ces écosystèmes, de nombreuses espèces commerciales y ont été exploitées (Koffi, 2016). La comparaison de ces valeurs montre que les habitats ont une densité identique. Cependant, nous avons observé que l'aire basale de la jachère est la plus faible. Ceci pourrait s'expliquer par le fait que plusieurs espèces disparaissent dans les jachères du fait de la pratique culturale sur brûlis.

Les forêts de la FCL ont des aires basales $\left(3,64-4,3 \mathrm{~m}^{2} / \mathrm{ha}\right)$ moins élevées que leur homologue du Parc National de la Marahoué (5,43 à 8,71 $\mathrm{m}^{2} / \mathrm{ha}$ ) (Dibi et al., 2008a) située dans le même secteur phytogéographique. 
Ce résultat montre le rôle des cultures dans la réduction du nombre des arbres de grands diamètres dans la forêt classée de Laouda.

\subsection{Cartographie de l'occupation du sol}

La discrimination spectrale de l'occupation du sol de la forêt classée de Laouda s'est effectuée par une interprétation des traitements numériques d'image Landsat TM 1986 et Landsat OLI 2017. L'utilisation de la classification supervisée par le réseau de neurone dans la caractérisation de l'occupation du sol a été effectuée avec succès. Les traitements numériques ont donc été validés par l'analyse statistique des résultats (matrices de confusions). Les matrices de confusion réalisées indiquent que les précisions cartographiques sont de $85 \%$ (1986) et $92 \%$ (2017). Les cartes obtenues sont de bonne qualité car, selon Pontius (2000), une étude d'occupation du sol est validée avec un coefficient de Kappa supérieur à $50 \%$. Les précisions cartographiques obtenues sont supérieurs à celles obtenues par Dibi et al. (2008a) et Chevalier (1998) qui ont respectivement obtenu des précisions globales de classification de $82,55 \%$ et $82 \%$ en traitant des images Landsat et Spot XS couvrant le Parc national de la Marahoué. La forte précision cartographique résulte des réseaux de neurone, comme l'ont fait remarquer Jofack et al. (2016) dans les Hauts Plateaux de l'Ouest Cameroun.

La couverture des forêts denses en 1986 était de 1648,2 ha, soit 41,35 $\%$ de la surface de la forêt classée de Laouda. A cette date, les cultures ne représentaient que 23,88 \% de la superficie totale de la FCL. En 2017, la couverture des forêts denses a nettement reculé. La superficie forestière actuelle est de 877,58 ha soit 22,02 \% de la FCL tandis que les surfaces occupées par les cultures ont connu un accroissement de 23,88\% à 55,99\%. Ainsi, la moitié de la surface des forêts denses de la FCL a disparu. Cela montre une forte pression sur les forêts denses de la FCL. Ce recul des forêts denses de la forêt classée de Laouda est dû à une forte augmentation des surfaces cultivées. Cette augmentation des surfaces cultivées est largement attribuée à la politique économique axée sur l'agriculture d'exportation. Ainsi, la forêt a été défrichée pour accroître les superficies des cultures d'exportation (UTCAF, 2018).

\subsection{Transformation et dynamique de l'occupation du sol}

Cette étude a montré une dissection des forêts denses et des sols nus, une fragmentation des forêts secondaires, une création et une agrégation des jachères et des cultures ainsi qu'une suppression des bas-fonds. Cette dynamique montre que ce sont les formations forestières et les bas-fonds qui ont été convertis en cultures et en jachères. Cette conversion des forêts (forêt dense et forêt secondaire) en culture a été soulignée par Freud et al. (2007). 
Ces auteurs ont montré que $89 \%$ des cultures en Côte d'ivoire, sont installées sur des défriches de forêts primaires et secondaires.

A l'échelle de la FCL, la régression des superficies des formations forestières et des bas-fonds entre 1986 et 2017 pourrait être attribuée à l'infiltration de ces espaces pour leurs mises en cultures. En effet, la dynamique d'intrusion dans cette forêt classée s'est faite dans les années 1980 correspondant au boom du cacao et du café en Côte d'Ivoire. La zone de la FCL, tout comme celle du Centre-ouest de la Côte d'Ivoire, est une zone de forte production de cacao (deuxième boucle du cacao) (Balac, 1999). Cette activité agricole se pratique dans la forêt et les bas-fonds. Ce qui a entrainé une forte pression sur les forêts de cette zone de forte production de cacao. Cette pression peut être due à divers facteurs, comme le développement des cultures d'exportations (café, cacao, hévéa.), le soutien des prix du café et du cacao, un code forestier peu précis et les techniques de culture sur brûlis. Les travaux de (Koné, 2015) ont souligné ces mêmes facteurs.

\section{Conclusion}

L'étude de l'impact des intrusions paysannes sur la physionomie et la dynamique de la végétation de la forêt classée de Laouda, a permis de discriminer les différents types d'occupation du sol. Ainsi, ont été identifiées : les forêts denses, les forêts secondaires, les cultures, les jachères, les bas-fonds et les sols nus.

L'étude de la dynamique de l'occupation du sol de 1986 à 2017 révèle une modification du paysage avec une déforestation de 770,62 ha (-19,33\%), la réduction des forêts secondaires de $31,16 \%$ et des bas-fonds de $11,65 \%$ et une augmentation des cultures de $32,11 \%$ et des jachères de 7,36 \% Au niveau de la physionomie, on note que la forêt de Laouda est perturbée. Elle comprend des arbres de petit diamètre dont l'aire basale varie de 1,06 à 4,3 $\mathrm{m}^{2} /$ ha et les densités de tiges sont faibles avec une valeur moyenne de 1275 tiges/ha.

Cette étude a permis de mettre l'accent sur l'impact négatif des intrusions paysannes à des fins de culture sur la forêt classée de Laouda. La réduction des surfaces de cette forêt ne peut pas être rattachée seulement aux intrusions paysannes. Ils convient de faire des études complémentaires qui consisteraient à élaborer la carte de vulnérabilité forestière aux défrichements agricoles à l'aide du Système d'Informations Géographiques (SIG). En vue de la restauration et de la réhabilitation de cette forêt, les décideurs devraient faire un suivi permanent de la FCL à partir des outils de télédétection. Cela permettra d'actualiser des cartes de l'occupation du sol et de déterminer les différents fronts d'anthropisation. Ceci accéléra les mesures d'aménagement des zones dégradées. 


\section{Remerciements}

Nous tenons à remercier la "United State Geological Survey" (USGS), pour la mise à disposition des images satellitaires utilisées dans cette étude et la SODEFOR pour l'autorisation d'accès aux forêts. Les auteurs de cet article expriment également leur reconnaissance au Centre Suisse de Recherches Scientifiques (CSRS), qui a contribué à l'identification des espèces végétales inventoriées.

\section{References:}

1. Adou Yao, C.Y. \& N'Guessan, E. K. (2005). Diversité botanique dans le sud du parc national de Taï, Côte d'Ivoire. Afrique Science 1: 295313.

2. Aké-Assi, L. \& Dian, B. (1988). Développement agricole et protection de la forêt. Quel avenir pour la forêt? Mitt. Inst. Allg. Bot. 23: 169176.

3. Aubréville, A. (1956). Essai de classification et de nomenclature des formations forestières africaines avec extension du système proposé à toutes les formations forestières du monde tropical. Nogent-Surmarne, France: Centre Technique de Foresterie Tropicale: 57 p.

4. Balac, R. (1999). Les économies pionnières prédatrices du milieu forestier: le cas de l'économie de plantation en Côte d'Ivoire. Société d'écologie humaine: $12 \mathrm{p}$.

5. Bamba, I. (2010). Anthropisation et dynamique spatio-temporelle de paysages forestiers en République Démocratique du Congo. Thèse, Université libre de Bruxelles (Université d'Europe), 250 p.

6. Bamba, I., Barima, Y.S.S. \& Bogaert, J. (2010). Influence de la densité de la population sur la structure spatiale d'un paysage forestier dans le bassin du Congo en R. D. Congo. Tropical Conservation Science 3: 31-44.

7. Barima, Y. S. S., Barbier, N., Bamba, I., Traoré, D.J. L. \& Bogaert, J. (2009). Dynamique paysagère en milieu de transition forêt-savane ivoirienne. Bois et Forêts des Tropiques 299: 15-25.

8. Bogaert, J., Ceulemans, R. \& Salvador-Van Eysenrode, D. (2004). Decision Tree Algorithm for Detection of Spatial Processes in Landscape Transformation. Environmental Management 33: 62-73.

9. Chauveau, J. P., Dozon, J. P. \& Richard, J. (1981). Histoires de riz, histoires d'igname: le cas de la moyenne Côte d'Ivoire. Africa 51: 621658.

10. Chevalier, J. F. (1998). Évaluation de l'imagerie spatiale haute résolution pour la cartographie et le suivi du couvert végétal des aires protégées et leur zone périphériques: cas du parc national de la Marahoué (Côte d'Ivoire). Mémoire de DEA Univ. Cocody. 63p. 
11. Chevalier, R., Gauthier, G. \& Archaux, F. (2010). Relevés floristiques pour le suivi de la biodiversité végétale des écosystèmes forestiers: éléments de réflexion pour faire les bons choix. Revue forestière française LXII-2: 141-154.

12. Devineau, J. I. (1984). Structure et dynamique de quelques forêts tropophiles de l'Ouest Africain (Côte d'ivoire), Thèse de Doctorat d'Etat ès sciences naturelles Université Paris VI, $294 \mathrm{p}$.

13. Dibi N'Da, H., Adou Yao, C. Y., N'Guessan, K. E., Koné, M. \& Sagne, Y. C. (2008b). Analyse de la diversité floristique du parc national de la Marahoué, Centre-Ouest de la Côte d'Ivoire. Afrique SCIENCE 04: $552-579$.

14. Dibi N'Da, H., N'guessan, K. E., Egnankou, W. M. \& Affian, K. (2008a). Apport de la télédétection au suivi de la déforestation dans le parc National de la Marahoué (Côte d'ivoire). Revue Télédétection 8: $17-34$.

15. Douffi, K. G.-C., Koné, M., Kouassi, K. I., N'Guessan, Y. J. \& Bakayoko, A. (2019). Farmer Establishmrnt Impact on the Forest Dynamic of Monogaga Protected Forest, in the Southwest of Côte d'Ivoire: Remote Sensing and Geographical Information Systems (GIS) Approach. European Journal of Engineering Research and Science 4: 12-20.

16. FAO (2011). Situation des forêts dans le monde 2011- Rapport principal. Etude FAO. Forêts. Rome, Italie, 201 p. (Disponible à l'adresse www.fao.org/forestry/fra/fra20 Il/fT).

17. Freud, E.H., Petithugenin, P. \& Richard, J. (2007). Les champs du cacao: un défi de compétitivité Afrique-Asie. Paris: Karthala, 117 p.

18. Guillaumet, J. L. \& Adjanohoun, E. (1971). La végétation de la Cote d'Ivoire. In: Le milieu naturel de Côte d'Ivoire. Avenard J-M, Eldin M, Girard G, Sircoulon J, Touchebeuf P, Guillaumet J-L, Adjanohoun E et Perraud (Eds), Mémoires ORSTOM, Paris, France 50: 161-263.

19. Hosni, G. (2002). Utilisation des réseaux de neurones pour la cartographie des zones humides à partir d'une série temporelle d'images RADARSAT 1, Thèse de Doctorat de l'Université du Québec, $230 \mathrm{p}$.

20. Jofack Sokeng, V.-C., Kouamé, F. K., Dibi N'da, H., Tankoano, B., Akpa You, L. \& Ngounou Ngatcha, B. (2016). Cartographie de l'occupation de sol des Hauts Plateaux de l'Ouest Cameroun par réseaux de neurones appliqués à une image LANDSAT 8 OLI. International Journal of Innovation and Scientific Research 23: 443454.

21. Kassin, K.E., Doffangui, K., Kouamé, B., Yoro, R.G. \& Assa, A. (2008). Variabilité pluviométrique et perspectives pour la replantation 
cacaoyère dans le Centre Ouest de la Cote d'Ivoire. Journal of Applied Biosciences 12: 633 - 641.

22. Koffi, M. (2016). Diversité végétale et structure de la végétation de la forêt des Marais Tanoe-Ehy au sud-est de la Côte d'Ivoire. Pour 1X obtention du Doctorat en Biologie végétale, Option Foresterie à 1XUFR Sciences de la Nature, Laboratoire de Botanique de 1×Université de Nangui Abrogoua (Abidjan). 170 p.

23. Koné, K. H. C., Boraud, N. K. M., Issali, A. E. \& Kamanzi, A. K. (2010). Influence du mode de plantage sur la survie et la dynamique de croissance des stumps de Teck utilisés dans les reboisements industriels en zone de forêt dense semi décidue de Côte d'ivoire. Journal of Applied Biosciences 32: 1956-1963.

24. Koné, M. (2015). Evolution du couvert forestier dense et impact de la déforestation sur la migration de la boucle du cacao en Côte d'Ivoire. Thèse de doctorat, Université Nangui Abrogoua (Abidjan), UFR Sciences de la nature, $166 \mathrm{p}$.

25. Koné, M., Kouadio, K., Kouadio, Y. L., Neuba, D. F. R., Malan, D. F. \& Coulibaly, L. (2014). Évolution de la couverture forestière de la Côte d'Ivoire des années 1960 au début du 21e siècle. International Journal of Innovation and Applied Studies 7: 782 - 794.

26. Kouadio, H. B. (2006). Apport de la télédétection et d'un systeme d'information géographique (SIG) à la gestion intégrée et participative des aires protégées en Côte d'Ivoire: application au parc national de Comoé (réserve de biosphère). Rapport d'étude UNESCO/MAB, 60 p.

27. Kouamé, N. M. T. (2000). Contribution à l'étude des plantes spontanées alimentaires du département d'Oumé (Côte d'Ivoire). Mémoire de DEA d'écologie tropicale, université de Cocody, Abidjan, Côte d'Ivoire, $122 \mathrm{p}$.

28. Kouassi, K. H., N'Guessan, K., Gnahoua, G. M. \& Kouassi, K. E. (2009). Flore post-culturale en zone de forêt dense semi décidue de côte d'Ivoire. Journal of Applied Biosciences 19: 1026-1040.

29. Krummel, J. R., Gardner, R. H., Sugihara, G., O’Neill, R. V. \& Coleman, P. R. (1987). Landscape pattern in a disturbed environment. Oikos 48: 321-324.

30. Lampin-Maillet, C., Bouillon, C., Long-Fournel, M., Morge, D. \& Jappiot, M. (2010). Guide de cartographie et caractérisation des interfaces habitat-forêt. Convention n²008 $119071 \mathrm{U}$ du ministère de l'Écologie, de l'Énergie, du Développement durable et de la Mer. $68 \mathrm{p}$. 
31. McGarigal, K. \& Cushman, S. A. (2002). Comparative evaluation of experimental approaches to the study of habitat fragmentation effects. Ecological Applications 12: 335-345.

32. N’Dri, M.-T. K. \& Gnahoua, G. M. (2008). Arbres et lianes spontanés alimentaires du département de Gagnoa (centre-ouest de la Côte d'Ivoire). Bois et forêts des tropiques 298: 65-75.

33. OIBT (2004). Étude de la composition floristique et de la combustibilité des jachères, friches et savanes autour des forêts classées de la Téné et de la Soungourou, 87 p.

34. Pontius, R. G. (2000). Quantification error versus location in comparison of categorical maps. Photogrammetrie Engineering and Remote Sensing 66: 1011 - 1016.

35. Sagne, Y. C., Adou Yao, Y. C. \& N'guessan, K. E. (2008). Transformations de la flore d'une forêt dense semi decidue: impact des activites humaines (Centre ouest de la Côte d'Ivoire). Agronomie Africaine 20: 1-11.

36. Schlaepfer, R. (2002). Analyse de la dynamique du paysage. Fiche d'enseignement 4.2, Laboratoire de Gestion des Ecosystèmes, Ecole Polytechnique de Lausanne, Suisse.

37. SODEFOR (2014). Carte de la végétation de la forêt classée de Laouda à l'échelle 1/30000 (document interne).

38. Song, C., Woodcock, C. E., Seto, K. C., Lenney, M. P. \& Macomber, S. A. (2001). Classification and change detection using Landsat TM data: When and how to correct atmospheric effects? Remote Sensing of environment 75: 230-244.

39. Toko, M. I., Toko, I. I., Sinsin, B. \& Touré, F. (2012). Indices de structures spatiales des îlots de forêts denses dans la région des Monts Kouffé. [VertigO] La revue électronique en sciences de l'environnement 12: URI: https://id.erudit.org/iderudit/1022694ar.

40. Trochain, J. L. (1957). Accord interafricain sur la définition des types de végétation de l'Afrique. Bull. Inst. Et. Centrafric. 13-14: 55-93.

41. UTCAF (2018). La côte d'ivoire à la reconquête de ses forêts. Rapport annuel de l'observatoire mondial de l'action climatique non étatique. www.climate-chance.org/wp-content/uploads/2018/12/fp17-utcatfcote-divoire_def.pdf. (Site consulté le 28 mai 2019): 14 p. 